\title{
Depression and anxiety among HIV patients in a treatment centre in Nigeria
}

\author{
Isabel N. Aika, Valentine U. Odili \\ University of Benin, Nigeria
}

\begin{abstract}
Introduction: Globally, the depression rate is increasing, and this has a bearing on patients with chronic disease conditions, including human immunodeficiency virus (HIV)/acquired immunodeficiency syndrome (AIDS). Depression is closely related to anxiety, both of which have a negative impact on a patient's quality of life and in achieving clinical outcomes. Depression and anxiety have been implicated in progression of HIV/AIDS. The purpose of this study is to determine the prevalence of depression and anxiety among HIV-positive patients and to determine their predictors.

Material and methods: A cross-sectional study was conducted among 305 HIV-positive patients attending the Central Hospital Antiretroviral Therapy Clinic. Outcome measures were: depression using the Patient Health Questionnaire (PHQ-9); and anxiety using the Generalised Anxiety Disorder (GAD-7) scale. Their associations with socio-demographic characteristics were analysed.

Results: The prevalence of depression was $24.6 \%$. Of these, $6.6 \%$ had clinically significant major depressive disorder. Age, sex, education, employment, income, co-morbidity, and smoking were not statistically significant factors for depression. Marital status, recent diagnosis, alcohol use, and anxiety were of statistical significance for depressive symptoms $(p<0.05)$. Prevalence of anxiety was $25.6 \%$; of these, 5.2\% had generalised anxiety disorder requiring further evaluation. $14.1 \%$ of depressed patients also had anxiety disorder. Marital status and recent diagnosis were predictors for anxiety.

Conclusions: One in four study participants had depression and anxiety. Co-morbid anxiety and depression was found in a considerable number of patients. Marital status, recent diagnosis of HIV, alcohol use, and adverse effects from antiretroviral drugs were predictors for depression.
\end{abstract}

HIV AIDS Rev 2019; 18, 2: 107-114

DOI: https://doi.org/10.5114/hivar.2019.86375

Key words: depression, anxiety, HIV, prevalence.

\section{Introduction}

United Nations AIDS (UNAIDS) reports that, globally, 36.7 million people were living with human immunodeficiency virus (HIV) as at the end of 2015 [1]. In Nigeria, an estimated 3.4 million ( $9 \%$ of the global epidemic) people are living with HIV, making the country the second highest HIV/acquired immunodeficiency syndrome (AIDS) burden

Address for correspondence: Isabel N. Aika, University of Benin, PMB 1154 Benin-Lagos road, 300001, Benin, Nigeria, phone: +2348082826539, e-mail: isabel.aika@uniben.edu

in the world after South Africa $[1,2]$. An estimated $60 \%$ of new HIV infections in Western and Central Africa in 2015 occurred in Nigeria [1].

Depression and anxiety are common mental disorders presenting alone or as a co-morbid disease state. Anxiety is either a component or a contributing factor of depression, while depression has a strong bi-directional relationship with chronic disease $[3,4]$. The World Health Organization

Article history:

Received: 16.01.2019

Received in revised form: 16.03.2019

Accepted: 21.03.2019

Available online: 27.06.2019
International Journal of HIV-Related Problems

HIV \& AIDS

R e vi e w 
(WHO) reports that about 300 million people worldwide suffer from depression, and it predicts that by 2030 depression will result in disability more than any other illness [4]. These conditions are more prevalent among HIV-positive patients than in the general population; a report shows that one in three persons with HIV infection will suffer from depression [5].

HIV/AIDS affects the mental health of those affected in many ways. HIV patients suffer more from depression and anxiety because they face adjustment reaction from diagnosis, a complicated treatment regimen, and reduced family and social support $[6,7]$. The role of stigmatisation in employment, health care, and housing-related settings is described as a chronic stressor that may contribute to difficulties in coping with the disease, inadequate self-care seeking behaviour, and decreased social interactions. Furthermore, concerns about the consequences of inadvertent illness disclosure could evoke anxiety and depression in HIV-positive patients [8].

The overall prevalence of depression and anxiety among HIV patients vary globally due to wide variations in sample sizes and characteristics, as well as the methodology for assessment of anxiety and depression [9-12]. In sub-Saharan Africa, where the burden of HIV infection is high, the estimated prevalence of depression among HIV patients on antiretroviral therapy is between $14 \%$ and $32 \%$; the pooled prevalence varies from one region to another based on the screening/diagnostic instrument and the cut-off point used in interpretation $[6,7]$. Validated instruments commonly used for assessing depression include the Schedule for Clinical Assessment of Neuropsychiatry (SCAN), Beck Depression Inventory (BDI-II), Patient Health Questionnaire (PHQ-9), Diagnostic and Statistical Manual of mental disorders (DSM-V), and the Centre for Epidemiological Studies Depression scale (CES-D). The PHQ-9 was found to have acceptable diagnostic properties for both screening and diagnosis of major depressive disorder in the preceding two weeks, and it is now commonly used in primary healthcare $[13,14]$. Few studies in Africa indicate the prevalence of anxiety among HIV patients in different countries. Ethiopia reports a prevalence of $32.4 \%$, while in South Africa $30.6 \%[6,9,11]$. Some tools used in screening for anxiety are the Generalised Anxiety Disorder (GAD) scale, State-Trait Anxiety Inventory (STAI), Beck Anxiety Inventory (BDI), and the Hospital Anxiety and Depression Scale (HADS), each varying in interpretation in terms of the nature of anxiety and scoring procedures [15]. Depression and anxiety both have a significant effect on the quality of life of patients, resulting in alteration of economic productivity, social isolation, progression of disability, and reduced ability to seek good medical care. Treatment failure from highly active antiretroviral agents, which are the mainstay in the treatment of HIV, due to non-adherence is closely linked to depression. Depression in people living with HIV/AIDS is also associated with poorer health outcomes including low weight gain, disease progression, and risk of suicide $[6,16]$.
Generally, depression and anxiety are underdiagnosed, which is more evident in resource-limited settings [17]. This study aims at determining the prevalence of depression and anxiety among HIV patients in Nigeria and to ascertain predictors of these conditions.

\section{Material and methods}

\section{Study design}

This study was a cross-sectional study conducted between May and June 2017 at the Pharmacy Unit of the Central Hospital Antiretroviral Therapy (CHART) Centre, an antiretroviral therapy (ART) clinic in a governmentowned secondary institution in Benin City, Nigeria.

\section{Study population}

The study was conducted among 305 patients from the CHART Centre. Patients were included in the study if they were HIV positive, including newly diagnosed patients on their first visit after diagnosis, and those who were within six months of diagnosis. Patients who were aged 18 years and showed willingness to fill the questionnaires were also included. Exclusion criteria included pregnant HIV-positive women, those who were not willing to fill the questionnaire, patients with tuberculosis, and patients who were mentally unstable. Convenience sampling was used in recruiting study participants.

\section{Ethical considerations}

This study was approved by the ethics and review committee of the Faculty of Pharmacy, University of Benin, Benin City with reference number EC/FP/018/04. All recruited participants were verbally informed about study objectives and the anonymity of the volunteered information. Only patients who verbally agreed to fill in the questionnaires were included.

\section{Data collection and instrument}

The questionnaire was the data collection tool, which consisted of three sections. Socio-demographic characteristics of patients, which included age, sex, employment, income, marital status, duration of HIV diagnosis, alcohol and cigarette use, other associated chronic illnesses and adverse effects made up section 1. Section 2 consisted of items from the Patient Health Questionnaire (PHQ-9), used to assess depressive symptoms in the past two weeks; a cut-off of $\geq 5$ was used to screen for depression, and a cut-off of 10 was used to screen for major depressive disorder or clinically significant depression. Section 3 had the Generalised Anxiety Disorder scale questions (GAD-7) for assessing anxiety; a cut-off of $\geq 5$ was used to screen for generalised anxiety in this study. Both tools were used to assess depression and anxiety in the two weeks prior to recruitment in the study. All items of both questionnaires were incorporated in this study. 
Table 1. Socio-demographic characteristics of respondents

\begin{tabular}{|c|c|c|}
\hline Variable & Frequency $(n)$ & Percentage (\%) \\
\hline \multicolumn{3}{|l|}{ Age (years) } \\
\hline $18-29$ & 64 & 21.0 \\
\hline $30-39$ & 108 & 35.4 \\
\hline $40-49$ & 70 & 23.0 \\
\hline$\geq 50$ & 63 & 20.65 \\
\hline Total & 305 & - \\
\hline \multicolumn{3}{|l|}{ Sex } \\
\hline Male & 72 & 23.6 \\
\hline Female & 233 & 76.4 \\
\hline \multicolumn{3}{|l|}{ Education } \\
\hline No formal & 10 & 3.3 \\
\hline Primary & 85 & 27.9 \\
\hline Secondary & 144 & 47.2 \\
\hline Post-secondary & 66 & 21.1 \\
\hline \multicolumn{3}{|l|}{ Employment } \\
\hline Public sector & 13 & 4.3 \\
\hline Private sector & 36 & 11.8 \\
\hline Self-employed & 215 & 70.5 \\
\hline Not employed & 41 & 13.4 \\
\hline \multicolumn{3}{|l|}{ Income (Naira) } \\
\hline$<18,000$ & 125 & 41 \\
\hline$\geq 18,000-<45,000$ & 81 & 26.6 \\
\hline$>45,000-<70,000$ & 29 & 9.5 \\
\hline $70,000-<100,000$ & 13 & 4.3 \\
\hline$>100,000$ & 10 & 3.3 \\
\hline None & 46 & 15.1 \\
\hline \multicolumn{3}{|l|}{ Marital status } \\
\hline Single & 70 & 23 \\
\hline Married & 158 & 51.8 \\
\hline Divorced/separated & 20 & 6.6 \\
\hline Partnered but not married & 12 & 3.9 \\
\hline Widow/Widower & 45 & 14.8 \\
\hline \multicolumn{3}{|l|}{ Duration of HIV diagnosis } \\
\hline$<6$ months & 86 & 28.2 \\
\hline 7-11 months & 8 & 2.6 \\
\hline 1-4 years & 103 & 33.8 \\
\hline 4-9 years & 88 & 28.9 \\
\hline$\geq 10$ years & 20 & 6.6 \\
\hline
\end{tabular}

\section{Data analysis}

Data were entered into MS excel, sorted, and exported into IBM SPSS version 20 for data analysis. Descriptive statistics was used to compute frequencies and proportion of variables. Differential means of variables were computed with
Table 2. PHQ-9 score of respondents

\begin{tabular}{l|c|c|c}
\hline Variable & PHQ-9 Score & $n$ & (\%) \\
\hline No depression & 0 & 80 & 26.2 \\
\hline Minimal depression & $1-4$ & 150 & 49.2 \\
\hline Mild depression & $5-9$ & 55 & 18 \\
\hline Moderate depression & $10-14$ & 16 & 5.2 \\
\hline Moderately severe depression & $15-19$ & 2 & 0.7 \\
\hline Severe depression & $20-27$ & 2 & 0.7 \\
\hline Total & & 305 & \\
\hline
\end{tabular}

ANOVA and Student's $t$-test using Graph pad Instat version 3. The significance of the results was considered in $p$-values of less than 0.05. Spearman correlation was performed to determine the relationship between depression and anxiety. The reliability and internal consistency of the GAD-7 and PHQ-9 were estimated by computing their Cronbach $\alpha$.

\section{Results}

The age range of study participants was 19-71 years, whereas the average age was close to 40 years $(39.3 \pm 11.1)$. One third of the patients (35.4\%) were aged 30-39 years, the majority of them were female (233 [74.6\%]), and about half (47.2\%) had attained a secondary level of education. 125 (41\%) had a monthly income of less than Naira (N) 18,000 (which is the national minimum wage in Nigeria). Ninety (29.5\%) patients reported that they drank alcohol, of whom $12(3.9 \%)$ drank it daily, 18 (5.9\%) drank it weekly, and 60 (19.7\%) sometimes drank alcohol. More than half of the participants (55.5\%) who drank alcohol were female, while 40 (44.4\%) were male. Most of the respondents were non-smokers - only $16(11.6 \%)$ admitted that they were smokers, with $14(75 \%)$ of the latter being males and four (25\%) being females. 203 (92.8\%) of the respondents did not have any other chronic illness, and only 7.2\% had other chronic illnesses that were being managed. Other details of the sociodemographic characteristics are as presented in Table 1.

The mean score of the Patient Health Questionnaire (PHQ-9) was $3.1 \pm 4.0$ with a Cronbach $\alpha$ of 0.803 , showing that the instrument is reliable in measuring depressive symptoms. As presented in Table 2, about three-quarters (75.4\%) of the study participants showed minimal depression or no depression, and 75 (24.6\%) of the respondents showed depressive symptoms ranging from mild to severe using a cut-off of 5 , this represents the prevalence of depression among participants. Using a cut-off of 10 on the PHQ-9, 20 (6.6\%) of the participants had clinically significant depression (see Table 3).

Major symptoms reported among patients were changes in sleep pattern $(n=115$ [44.4\%]), feeling tired or loss of energy $(n=142[46.3 \%])$, and feeling bad that they let themselves or their family down $(n=91$ [32\%]). Nineteen (6.3\%) patients had thoughts of being better off dead or hurting themselves, 
Table 3. Responses of participants to question 9 of the PHQ-9 (Thoughts that you would be better off dead, or of hurting yourself in some way?)

\begin{tabular}{l|c|c|c|c|c|c}
\hline Duration of HIV diagnosis & $\begin{array}{c}\leq 6 \text { months } \\
n(\%)\end{array}$ & $\begin{array}{c}7-11 \text { months } \\
n(\%)\end{array}$ & $\begin{array}{c}>1-4 \text { years } \\
n(\%)\end{array}$ & $\begin{array}{c}>4-9 \text { years } \\
n(\%)\end{array}$ & $\begin{array}{c}\geq 10 \text { years } \\
n(\%)\end{array}$ & Total (\%) \\
\hline Not at all & $78(90.7)$ & $8(100)$ & $95(92.2)$ & $87(98.8)$ & $18(0.9)$ & $286(93.7)$ \\
\hline Several days & $4(4.6)$ & 0 & $7(6.8)$ & $1(1.2)$ & $1(1.0)$ & $13(4.3)$ \\
\hline More than half the days & $1(1.2)$ & 0 & 0 & 0 & $1(0.1)$ & $2(0.7)$ \\
\hline Nearly everyday & $3(3.5)$ & 0 & $1(0.97)$ & 0 & 0 & $4(1.3)$ \\
\hline Total $(\%)$ & $86(28.2)$ & $8(26.6)$ & $103(33.8)$ & $88(28.8)$ & $20(65.6)$ & 305 \\
\hline
\end{tabular}

Table 4. Generalised Anxiety Disorder (GAD-7) score of respondents

\begin{tabular}{l|c|c|}
\hline Variable & GAD-7 score & Frequency (\%) \\
\hline No anxiety disorder & $0-4$ & $225(74.4)$ \\
\hline Mild anxiety disorder & $5-9$ & $56(18.4)$ \\
\hline $\begin{array}{l}\text { Moderate anxiety } \\
\text { disorder }\end{array}$ & $10-14$ & $16(5.2)$ \\
\hline Severe anxiety disorder & $\geq 15$ & $6(2.0)$ \\
\hline Total & & 305 \\
\hline
\end{tabular}

while 19 (6.3\%) of the respondents had suicide ideation ranging from several days to nearly every day in the past two weeks. Table 4 shows that eight (42.1\%) of those with suicide ideation were patients diagnosed in the past six months.

The mean depressive scores were determined along with their association with the socio-demographic characteristics of participants. Age, sex, education, employment, income, co-morbidity, and smoking were not statistically significant predictors of depression. Patients who had shorter duration ( $<6$ months) of HIV diagnosis had a statistically higher depression score than those with duration of 1-4 years $(p<0.01)$ and those $>4-9$ years $(p<0.01)$, while patients who drank alcohol had a higher depression score than non-alcohol users $(p<0.01)$ (Table 5$)$. Forty-three patients who had generalised anxiety disorder had high depression score; thus, anxiety accounted for $14.1 \%$ of depressed participants, with a positive correlation coefficient of $r=0.74(p<0.01)$.

Eighty-eight $(25.6 \%)$ of the respondents had anxiety disorder as measured by the Generalized Anxiety Disorder (GAD-7) scale. Of these, $7.2 \%$ had generalised anxiety disorder. The mean score was $3.2 \pm 3.8$, with a Cronbach $a$ co-efficient of 0.825 (Table 6). Major symptoms of anxiety reported by patients in the previous two weeks from the GAD-7 scale were feeling afraid as if something bad might happen ( $n=165$ [54.1\%]), feeling anxious or nervous $(n=156$ [49.9\%]), getting easily annoyed or irritated $(n=111[36.4 \%])$, and having trouble relaxing $(n=75[24.6 \%])$.

Factors associated with anxiety among participants were marital status and duration of HIV diagnosis and treatment. Participants who were single had statistically significant high- er anxiety score than those who were married $(p<0.01)$, while patients who were recently diagnosed (less than six months) had a higher score than those diagnosed between 1 and 4 years $(p<0.01)$ and those diagnosed between 4 and 10 years $(p<0.01)$. Age, sex, employment, income, co-morbidity, alcohol use, and smoking were not predictors of anxiety (see Table 6).

\section{Discussion}

\section{Prevalence of depression}

The prevalence of depression was $24.6 \%$, using cut-off of 10 with the PHQ-9, $6.6 \%$ of the participants met the criteria for clinically relevant depression. The prevalence of depression from this study is comparable with a previous study conducted in another setting in Benin City. There was a prevalence of $29.3 \%$ of depression among HIV patients using both the Schedule for Clinical Assessment of Neuropsychiatry (SCAN) and the Beck Depression Inventory [19]. In that study, $14.7 \%$ of those depressed had mild symptoms, $12 \%$ had moderate symptoms, and $1.3 \%$ had severe depression, which is lower than that observed in this study. A higher rate (39.9\%) of depression has been reported using the PHQ-9 in Eastern Nigeria [18]. In Northern Nigeria, $21.3 \%$ of participants were depressed according to the CES-D scale, $14.2 \%$ of whom met the diagnostic requirement for depressive disorder [10], while a figure of $23.1 \%$ was reported in Western Nigeria [12]. In North-Central Nigeria $56.7 \%$ of patients had depressive symptoms - the authors adopted the PHQ-9 as a screening tool for depression, as employed in this study, but they used a different cut-off $(\geq 1)$, which included patients with minimal depression [16]. Higher rates of depression have been reported in some parts of Africa, 66\% in Uganda, and in two centres in Ethiopia, $45.8 \%$ and $41.2 \%$ were reported, respectively. In Cameroun $20 \%$ has been reported, and 30.6\% in South Africa [7, 20-23]. Variations in the prevalence of depression may be due to differences in diagnostic tools and criteria, sample size, and interpretations by the authors in the various studies $[13,14]$.

\section{Suicide ideation among HIV patients}

Suicide ideation was common in $6.3 \%$ of the respondents in this study. It was observed that not only the newly 
Table 5. Relationship between depression and socio-demographic factors of respondents

\begin{tabular}{|c|c|c|}
\hline Variable & Mean \pm SD & $p$-value \\
\hline \multicolumn{3}{|l|}{ Age (years) } \\
\hline $18-29$ & $3.250 \pm 3.733$ & \multirow[t]{4}{*}{0.2814} \\
\hline $30-39$ & $3.370 \pm 3.990$ & \\
\hline $40-49$ & $3.130 \pm 5.054$ & \\
\hline$\geq 50$ & $2.190 \pm 2.596$ & \\
\hline \multicolumn{3}{|l|}{ Sex } \\
\hline Male & $3.389 \pm 0.531$ & \multirow[t]{2}{*}{0.4087} \\
\hline Female & $2.190 \pm 2.596$ & \\
\hline \multicolumn{3}{|l|}{ Education } \\
\hline$<12$ years & $3.060 \pm 3.437$ & \multirow[t]{3}{*}{0.2518} \\
\hline Secondary & $3.611 \pm 3.748$ & \\
\hline Post-secondary & $3.422 \pm 3.563$ & \\
\hline \multicolumn{3}{|l|}{ Employment } \\
\hline Employed & $2.996 \pm 3.905$ & \multirow[t]{2}{*}{0.5566} \\
\hline Not employed & $3.390 \pm 4.499$ & \\
\hline \multicolumn{3}{|l|}{ Income (Naira) } \\
\hline$\leq 18,000$ & $3.080 \pm 3.555$ & \multirow[t]{2}{*}{0.9456} \\
\hline$>18,000->100,000$ & $3.050 \pm 4.549$ & \\
\hline \multicolumn{3}{|l|}{ Marital status } \\
\hline Single & $4.600 \pm 5.100$ & \multirow[t]{2}{*}{$0.0006^{*}$} \\
\hline Married & $2.513 \pm 3.690$ & \\
\hline Single & $4.600 \pm 5.100$ & \multirow[t]{2}{*}{$0.0271^{*}$} \\
\hline Divorced/separated & $2.900 \pm 3.155$ & \\
\hline Married & $2.513 \pm 3.690$ & \multirow[t]{2}{*}{0.3990} \\
\hline Divorced/separated & $2.900 \pm 3.155$ & \\
\hline \multicolumn{3}{|l|}{ HIV duration of diagnosis } \\
\hline$<6$ months & $4.558 \pm 5.390$ & \multirow[t]{2}{*}{$0.0048^{*}$} \\
\hline $1-4$ years & $2.689 \pm 3.545$ & \\
\hline$<6$ months & $4.558 \pm 5.390$ & \multirow[t]{2}{*}{0.385} \\
\hline$\geq 10$ years & $3.000 \pm 3.195$ & \\
\hline$<6$ months & $4.558 \pm 5.390$ & \multirow[t]{2}{*}{$<0.0001^{*}$} \\
\hline$>4-10$ years & $2.231 \pm 2.621$ & \\
\hline \multicolumn{3}{|l|}{ Co-morbid disease } \\
\hline Yes & $3.136 \pm 3.060$ & \multirow[t]{2}{*}{0.9154} \\
\hline No & $3.042 \pm 4.052$ & \\
\hline \multicolumn{3}{|l|}{ Alcohol } \\
\hline Yes & $4.033 \pm 4.777$ & \multirow[t]{2}{*}{$0.0051^{*}$} \\
\hline No & $2.637 \pm 3.533$ & \\
\hline \multicolumn{3}{|l|}{ Smoking } \\
\hline Yes & $2.750 \pm 2.408$ & \multirow[t]{2}{*}{0.7582} \\
\hline No & $3.066 \pm 4.050$ & \\
\hline
\end{tabular}

Table 6. Relationship between anxiety and socio-demographic factors of respondents

\begin{tabular}{|c|c|c|}
\hline Variable & Mean \pm SD & $p$-value \\
\hline \multicolumn{3}{|l|}{ Age (years) } \\
\hline $18-29$ & $3.250 \pm 3.367$ & \multirow[t]{4}{*}{0.1440} \\
\hline $30-39$ & $3.833 \pm 4.244$ & \\
\hline $40-49$ & $2.886 \pm 3.854$ & \\
\hline$\geq 50$ & $2.556 \pm 2.966$ & \\
\hline \multicolumn{3}{|l|}{ Sex } \\
\hline Male & $3.208 \pm 4.621$ & \multirow[t]{2}{*}{0.9565} \\
\hline Female & $3.236 \pm 3.457$ & \\
\hline \multicolumn{3}{|l|}{ Employment } \\
\hline Employed & $4.231 \pm 3.412$ & \multirow[t]{2}{*}{0.4213} \\
\hline Not employed & $3.512 \pm 3.835$ & \\
\hline \multicolumn{3}{|l|}{ Income (Naira) } \\
\hline$\leq 18,000$ & $3.464 \pm 3.247$ & \multirow[t]{2}{*}{0.3030} \\
\hline$>18,000->100,000$ & $2.984 \pm 4.043$ & \\
\hline \multicolumn{3}{|l|}{ Marital status } \\
\hline Single & $4.129 \pm 4.107$ & \multirow[t]{2}{*}{0.0083} \\
\hline Married & $2.728 \pm 3.51$ & \\
\hline Single & $4.129 \pm 4.107$ & \multirow[t]{2}{*}{0.4750} \\
\hline Divorced/separated & $3.723 \pm 4.110$ & \\
\hline Married & $2.728 \pm 3.51$ & \multirow[t]{2}{*}{0.0659} \\
\hline Divorced/separated & $3.723 \pm 4.110$ & \\
\hline \multicolumn{3}{|l|}{ HIV duration of diagnosis } \\
\hline$<6$ months & $4.477 \pm 0.575$ & \multirow[t]{2}{*}{0.0003} \\
\hline $4-10$ years & $2.45 \pm 3.024$ & \\
\hline$<6$ months & $4.477 \pm 0.575$ & \multirow[t]{2}{*}{0.0065} \\
\hline $1-4$ years & $2.854 \pm 3.521$ & \\
\hline $1-4$ years & $2.854 \pm 3.521$ & \multirow[t]{2}{*}{0.3756} \\
\hline$>4-10$ years & $2.45 \pm 3.024$ & \\
\hline \multicolumn{3}{|l|}{ Co-morbid disease } \\
\hline Yes & $2.909 \pm 3.351$ & \multirow[t]{2}{*}{0.6785} \\
\hline No & $3.254 \pm 3.790$ & \\
\hline \multicolumn{3}{|l|}{ Alcohol } \\
\hline Yes & $3.023 \pm 3.606$ & \multirow[t]{2}{*}{0.1385} \\
\hline No & $3.722 \pm 4.070$ & \\
\hline \multicolumn{3}{|l|}{ Smoking } \\
\hline Yes & $3.235 \pm 3.822$ & \multirow[t]{2}{*}{0.9092} \\
\hline No & $3.125 \pm 2.306$ & \\
\hline
\end{tabular}

diagnosed patients had suicide ideation, but some patients who had been diagnosed for more than 10 years also experienced suicide ideation, although the representation of the latter category of patients was low; more studies will be needed in this regard in the future. Participants with suicide ideation from our study amounted to more than the $2.9 \%$ 
reported in a 12-month study conducted in Northern Nigeria - the study reported that $2.3 \%$ of them eventually attempted suicide [16]. In another study in Kaduna, Nigeria the risk of suicidality among HIV-positive patients was $16 \%$, of whom $9 \%$ had high risk of suicidality [24]. These facts highlight the impact of depression on HIV-positive patients.

\section{Predictors of depression}

Age, sex, and presence of other illness were not predictors of depression from this study. Depression can occur at any age, and it occurs in individuals at different times of their lives for different reasons [22]. In similar studies, age has not been reported as a factor for depression [18, $21,25]$. Women are said to suffer 2-3 times more often from depression than males, which has been reported in multiple studies [7, 18]. Conversely, a study in South Africa observed that the prevalence was almost the same in both sexes [26]. Irrespective of the fact that women made up more than $70 \%$ of this study population, sex was not a defining contributor for depression. This study, however, confirms the report of feminisation of HIV infection in underdeveloped countries because about $60 \%$ of HIV-positive patients in Nigeria are female, and within the age range of 15-24 years females are three times more likely to be infected with HIV than males [27, 28].

Low-income earners were not more depressed than high-income earners in this study. However, many studies link low socioeconomic status with depression among HIV patients. In a study in Nigeria, the highest prevalence for depression was found among respondents who earned less than $\$ 20,000$ (minimum monthly income in Nigeria), and the same report was made in studies conducted in sub-Saharan Africa, Ethiopia, and Canada, where low-income earners experienced more depression [16, 21, 29, 30]. Since half of the study participants were married, there may be a possibility of financial support from a spouse or from relatives, which could be an explanation for the observed deviation.

The presence of a co-morbid state is an important factor for depression. Physical co-morbidities such as diabetes, hypertension, respiratory problems, and reproductive abnormalities in addition to HIV infection increases the risk of depression [31]. This study did not, however, ascertain the specific chronic conditions that the affected patients had.

Surprisingly, smoking was not a risk factor for depression in this study, contrary to its link with depression in other studies $[32,33]$. In a longitudinal study of HIV-infected and matched infected veterans in care, prior smoking due to nicotine dependence was associated with alcohol intake and depression [33]. Fewer patients were smokers in this study compared to more than $50 \%$ of smokers among HIV-positive patients in the USA [33]. The reason for this observation may be due to the fact that few respondents reported engaging in the habit of smoking in this study because smoking is not culturally, religiously, or socially accepted in this region. Similar to smoking, alcohol use increases risk of depression among HIV-positive patients, as corroborated by results in this study [32]. The quantity and extent of alcohol use among participants were not determined, which is a limitation of the present study. The prevalence of alcohol-related problems including their impact on depression among HIV-positive patients ranged from 22 to $60 \%$ [33, 34]. Alcohol misuse has been shown to be positively associated with depression, and findings show that quitting alcohol drastically diminishes depressive symptoms [32]. In addition to increasing risk for depression, alcohol misuse is linked to viral replication and HIV progression, thus impeding achievement of positive treatment outcomes [35].

HIV-positive patients in this study, who were married, had statistically significant lower depressive scores than single, divorced, or separated patients with HIV infection. This finding is supported by the Canadian Community Health Survey, in which the lowest rate of depression was seen among those who were married, and the highest depression rate was reported among those who were divorced or separated [36]. In India, similar finding was observed: it was noted that patients who were divorced or widowed had to deal with the stress of taking care of their children and families. These patients may also have been burdened with guilt and shame, thus suffering from social withdrawal as a way to escape disclosure of their status and stigmatisation by society. The loss of their loved ones, which may be due to HIV infection, could also take a toll on them $[37,38]$.

Newly diagnosed patients and those less than six months since diagnosis were more depressed than patients $>1-10$ years since diagnosis. In a STEP study conducted in Texas, USA, a high prevalence of depression occurred in newly diagnosed patients; the report concluded that newly diagnosed HIV-positive patients were 2-3 times more likely to be at high risk for depression. The increased risk among these patients could be due to an adjustment reaction to recent notification of seropositivity or due to distress secondary to HIV-related symptoms; this is because some of these patients may already have been symptomatic, which warranted their agreeing to screening for seropositivity [38].

\section{Prevalence and predictors of anxiety}

Anxiety was strongly associated with depression in this study and was thus a predictor of depression. One in four of our study participants had anxiety disorder. Of these, $14.1 \%$ also had depression. A higher anxiety rate of $32.4 \%$ and co-morbid depression of $24.5 \%$ among HIV patients was reported in Ethiopia, and $36 \%$ in India [21, 28]. Predictors for depression interplay with anxiety because anxiety precedes depression $[28,36]$. Being unmarried and recent diagnosis of HIV were strongly associated with anxiety. Those recently diagnosed experience adjustment disorder, which usually occurs after receiving an HIV diagnosis - feelings of guilt, shame, and fear about the outcome of the infection. The most common symptoms reported from the individual items of the GAD were feeling afraid as if something bad might happen, feeling nervous and anxious, difficulty in relaxing, and becoming easily annoyed or irritable. This is well 
documented because these patients feel socially stigmatised together with the emotional trauma they might have experienced, and the stress of adjusting to the new state of health can result in anxiety [28]. Anxiety due to adjustment problems tends to diminish with time - in a study conducted among a national sample of persons living with HIV, it was observed that generalised anxiety disorder was high following initial diagnosis of the infection, but significantly decreased with time $[39,40]$.

Integration of mental health care services with essential care for HIV-positive patients is crucial to forestalling the prevalence and the negative impact of depression and anxiety in these patients. Recently, the WHO recommended mental health assessment and management for all people living with HIV infection, but only a few countries have started implementing programmes to address this issue [41].

In addition to some limitations already mentioned, the timeframe of the study was short, thus patients with temporal depression might have been included. The study was conducted in only one treatment centre for HIV/AIDS and among a subset of patients, thus the results from this study cannot be generalised. Since this is a self-report-based survey, issues with report bias cannot be excluded.

\section{Conclusions}

This study indicates that depression and anxiety disorders are common mental problems among HIV-positive patients. These symptoms occur more in HIV patients who are single, those newly diagnosed, and alcohol users. HIV patients with generalised anxiety disorder were more prone to developing depression. Mental health care integration in the context of HIV care should be encouraged because routine assessment to screen patients who develop psychiatric symptoms of depression and/or anxiety will aid in prevention, early diagnosis, and treatment of depressive patients.

\section{Conflict of interest}

The authors declare no potential conflicts of interest with respect to the research, authorship, and/or publication of this article.

\section{References}

1. UNAIDS 2016 - Fact Sheet, Latest Statistics on the Status of AIDS. Available at: www.unaids.org/en/resources/factsheet (Accessed: 18.07.2017).

2. National Agency for Control of AIDS NACA 2016 - naca.gov.ng/ test/publications Global AIDS Response Country Progress Report (Accessed: 18.07.2017)

3. Boris V, William D, Rahn B. Depression and chronic diseases: it is time for a synergistic mental health and primary care approach. Prim Care Companion CNS Disord 2013; 15: pcc.1210-1468.

4. WHO, 2017. Depression. Available at: www.who.int/mediacenter/ factsheets/fs369/en/ (Accessed: 18.07.2017).

5. Bing F, Burman M, Longshove D. The estimated prevalence of psychiatry disorder, drug use and drug dependence among people with HIV disease in United States. Results from the cost and service HIV utilization study. Arch Gen Psychiatry 2001; 58: 79.
6. Bernard C, Dabis F, De Rekeniene N. Prevalence and factors associated with depression in people living with HIV in sub Saharan Africa: a systematic review and meta-analysis. PLoS One 2017; 12: e0181960.

7. Getachew T, Getinet A, Tadesse A, et al. Prevalence and correlates of depression and anxiety among patients with HIV on follow up at Alert Hospital, Addis Ababa, Ethiopia. BMC Psychiatry 2016; 16: 368 .

8. Peter A, Micheal P, Donald C, Rae A. Impact of HIV-related stigma on health behaviours and psychological adjustments among HIVpostive men and women. AIDS Behav 3006; 10: 473-482.

9. Chikezie U, Otakpor A, Kutey O, James B. Depression among people living with HIV/AIDS in Benin City Nigeria: a comparative study. Nigerian Journal of Clinical Practice 2013; 16: 234-242.

10. Olisah V, Baiyewu O, Sheikh T. Adherence to highly active antiretroviral therapy in depressed patients with HIV/AIDS attending a Nigerian University Teaching Hospital. Afr J Psychiatry (Johannesburg) 2010; 13: 275-279.

11. Iwudibia O, Brown A. HIV and depression in Eastern Nigeria: the role of HIV-related stigma. AIDS Care: Psychological and Sociomedical Aspects of HIV/AIDS 2014; 26: 5.

12. Adetunji O, Adegboyega O, Adebowale T. Prevalence and predictors of depression in People Living with HIV/AIDs attending an Outpatient clinic in Nigeria. Iran J Psychiatry Behav Sci 2014; 26-31.

13. Laura K, Len D Jr. Screening tools for depression in primary care. West J Med 2001; 175: 349-352.

14. Laura M, Simon G. The optimal cut-off scores for diagnosing depression with the PHQ-9: a meta-analysis. CMAJ 2012; 184: E191-E196.

15. Rinad S, Rebecca E, Lucia W, Steven L. Free, brief and validated standardized instruments for low-resource Mental Health settings. Cogn Behav Pract 2015; 22: 5-19.

16. Catherine O, Patrick S, Ernest E, et al. Depression, suicidality and alcohol use disorder among people living with HIV/AIDS. Nigeria BMC Public Health 2017; 17: 542.

17. Bhatia M, Munjal S. Prevalence of depression in people living with HIV/AIDS undergoing ART and factors associated with it. J Clin Diagn Res 2014; 8: WC01-WC04.

18. Aguocha CM, Uwakwe RU, Duru CB, et al. Prevalence and social demographic determinants of depression among patients attending HIV/AIDS clinic in a Teaching Hospital in Imo State, Nigeria. American Journal of Medical Sciences and Medicine 2015; 3: 106-112.

19. Shittu R, Issa B, Olarewaju G, et al. Prevalence and correlates of depressive disorders among PLWHA in North Central Nigeria. J AIDS Clin Res 2013; 4: 11

20. Shamba C, Atukunda R, Imakit R, Memiah P. Prevalence of depressive symptoms amongst highly active antiretroviral therapy (HAART) patients in AIDSRelief Uganda. J Public Health Africa 2013; 4: e19.

21. Mahir M, Bezatu M, Yadeta D, Wanzahun G. Prevalence of depression and associated factors among HIV patients seeking treatments in ART clinics at Harar Town, Eastern Ethiopia. J AIDS Clin Res 2015; 6: 474 .

22. Pappin M, Wouters E, Booysen F. Anxiety and depression among patients enrolled in public sector antiretroviral treatment program in SA: a case study. BMC Public Health 2012; 12: 244.

23. Bradley N, Brian W, Atashili J. Prevalence and predictors of major depression in HIV infected patients on Antiretroviral therapy in Bamenda, a semi-urban center in Cameroon 2012. Availabel at: www.doi.org/10.1371// (Accessed: August 2017).

24. Aremu S, Nuhu F, Ajayi O. Sucidcality among HIV patients and treatment center in Kaduna metropolis. Nigeria School Medical Journal 2016; 19: 196-200.

25. President and Fellows of Harvard College. Depression, Sex and Age. Havard Health Publications, Cambrigde, MA. 2007; 1-5.

26. Mossa M, Jenna F. Treating depression in HIV/AIDS. South African Journal of Psychiatry 2007; 13: 86-89. 
27. Drissia S, Yentema O, Mahammad H, et al. What explains gender inequalities in HIV/AIDs prevalence in sub-Saharan Africa? Evidence from the Demographic and Health Survey. BMC Public Health 2016; 10: 1136.

28. NACA report: Gender Responsive budgeting milestones, HIV/ AIDs programming (2017). https://naca.gov.ng/gender-responsivebudgeting-milestones-hivaids-programming/ (Accessed: November 2017).

29. Chaudhury S, Bakhla A, Saini R. Prevalence, impact and management of depression and anxiety in patients with HIV: a review. Neurobehavioral HIV Medicine 2016; 7: 15-30.

30. Offord D, Boyle M, Campbel D, et al. One year prevalence of psychiatric disorder in Ontarians 15 to 64 years of age. Can J Psychiatry 1996; 41: 559-563.

31. Havlik R, Brennan M, Karpiark S. Co-morbidities and depression in older adults with HIV sexual. Health 2011; 8: 551-559.

32. Shiva R, Mary EW, Susan K, et al. Cigarette smoking in the HIVinfected population. Proc Am Thorac Soc 2011; 8: 313-319.

33. Braithwaithe S, Yixin F, Tate J, et al. Do alcohol misuse, smokers and depression vary concordantly or sequentially. A longitudinal study of HIV infected and matched infected veterans in care. AIDS Behav 2016; 20: 566-572.

34. Wei-Ti C, Cheng-Shi S, Joyce P, et al. Antiretroviral therapy (ART) side effect impact on quality of life, and depressive symptomatology: a mixed-method study. J AIDS Clin Res 2014; 5: 418.

35. Sullivan LF, Goulet J, Amy C. Alcohol consumption and depressive symptoms over time: A longitudinal study of patients with or without HIV infection. Drug Alcohol Depend 2011; 117: 158-163.

36. Akhtar-Danesh N, Landeen J. Relation between depression and socio-demographic factors. International Journal of Mental Health Systems 2007; 1: 4334.

37. Bhatia MS, Sahil M. Prevalence of depression in people living with HIV/AIDS undergoing ART and factors associated within. Int J Clin Diagn Res 2014; WCO1-WCO4.

38. Bhatia R, Hartman C, Kallen MA, et al. Persons newly diagnosed with HIV infection are high risk for depression and poor linkage care: results from the Steps Study. AIDS Behav 2011; 15: 1161-1170.

39. Tsao JC, Dobalian A, Naliboff BB. Panic disorder and pain in a national sample of persons living with HIV. Pain 2004; 109: 172-180.

40. Olley BO, Adebayo KO, Ogunde MJ, et al. Psychosocial factors predicting depression treatment-seeking HIV/AIDS patients: a multisite Nigerian study. Nigerian Journal of Clin Practice 2017; 20: 296-302.

41. Let's talk: depression among people living with HIV (2017). Available at: www.who.int./hiv/mediacenter/news/hiv-depression/en (Accessed: September 2017). 